\title{
Matters of Time: Materiality and the changing temporal organisation of everyday energy consumption
}

\begin{abstract}
This paper seeks to reverse an emphasis in current discussions of peak demand and the times of everyday energy consumption, which suggest that the use of technologies, infrastructures and energy are patterned by temporal features of practice as against such materials being integral to practice temporalities. In an exploratory study of homes and daily lives between 1950 and 2000, materials are foregrounded in the analysis of daily routines and the temporal details of specific practices - doing laundry, keeping warm and keeping oneself clean. The paper challenges prominent approaches by demonstrating the material co-constitution of practice temporalities, and thus of the temporal organization of everyday energy consumption. This material co-constitution is argued for in two ways. Firstly, the paper reveals the material dimensions of commonly cited concepts of temporality from Zerubavel (1985), which have previously relied on solely social explanations. Secondly, the Paper argues that understanding materials as integral to times of practice (and consumption) requires a new conceptual vocabulary with which to perceive, analyse and discuss such relationships. The paper concludes by outlining an initial set of concepts identified through the historical study, and discusses the relevance of the emergent framework to contemporary contexts.
\end{abstract}

\section{Introduction}

The timing of everyday energy consumption - why energy is used in the home at particular times of day, week and year - is a pertinent topic in discussions of peak demand and renewable supply. In reaction to prominent (but problematic) understandings of peaks, which are viewed as inevitable (Strengers, 2013) and addressed through ecoinnovation, pricing tariffs and consumer information (Strbac, 2008; Torriti, 2015; Darby and McKenna, 2012), recent research has focused on what energy is for (Shove and Walker, 2014; Strengers, 2012, 2013), and thus the social practices performed at peak times (Anderson, 2016; Torriti, 2017). However, this reframing itself contains a problematic emphasis, for it creates the illusion that practices overlay and consume the material world in synchrony with their own rhythms. This paper seeks to modulate this reframing by exploring and developing concepts with which to analyse the material coconstitution of practice temporalities and thus reveal how technologies and infrastructures partly shape temporal patterns of energy consumption.

Materials and time are prominent in accounts of social practices. The inclusion of the material has been integral to developments in practice theory within studies of consumption (Warde, 2005; Shove et al, 2012; Shove and Spurling, 2013; Hui et al, 2016). Initially repositioning material consumption as defining of and a conduit for a 
practice's performance (Warde, 2005), recent debates on materials in practice have unfolded in two ways. The first is concerned with how 'the material' should be conceptualised in relation to practice - for example do materials precede practice? are they co-constituted by practice? (Shove et al, 2015), the second is concerned with the conflation of different forms of materiality discussed under the term 'material' (Maller et al, 2016), and the intellectual potential of opening out this category such that material phenomenon and their interactions with one another might be studied in their own right.

For example, on the former point, materials might be conceptualised as an 'element' of practice, which combine with meanings and skills in specific performances (Shove et al, 2012). Showering practices combine showers, heated water, shower gel and sponges with skills (e.g. turning on the shower), and meanings (e.g. cleanliness and freshness) to accomplish a morning shower. Materials are viewed as co-constitutive of practice and vice versa, as such they are not simply adopted or used, but rather come to have meaning and are combined, adapted and sometimes reconfigured in use. This contrasts with Schatzki's (2010) concept of 'material arrangements', which in comparison to Shove et al, draws attention to the spatializing qualities of built environments and infrastructures (e.g. such as road infrastructures, or the layout of buildings).

Though the latter point is less useful for this paper, the focus on infrastructure espies a second point of debate; that 'the material' is a broad category, including technologies and portable objects, resources (such as energy and water) as well as infrastructures and built environments. Grouping these eclectic phenomenon under a single term ('the material') creates potential oversights in understandings of consumption because it precludes studying how materials themselves change over time, how the same material might be part of multiple practices, and how different types and combinations of material interact with one another, both in moments of practice performance, and in between such performances.

The position developed in this paper draws together several of these aspects. I share the central premise of Shove et al (2012) that materials co-constitute practice. However, in line with recent developments (e.g. Maller et al, 2016) I explicitly focus on different types of materiality to explore how materials combine in (or prior to/ after) performance. As noted the interest is in the implications of different forms of materials and their combination in practice for the temporal organization of practices which consume energy in the home.

As well as offering accounts of materials, practice theories provide an analysis of temporalities of everyday life and consumption too. For example, it is acknowledged that that the consumption (of stuff) in practice 'makes' time (Shove et al, 2009:3), whether enabling practitioners to slow time down, or compelling them to maintain and repair the temporally deteriorating material of a wooden boat (Jalas, 2006). Likewise, it has been shown that experiences of time, such as harry, hurry and time squeeze are an outcome of the co-ordinations of people and practices in everyday life (Southerton, 2003, Spurling, 2015). Despite these accounts and the acknowledgement that materials are implicated in the temporal characteristics of social practices there has been limited systematic 
empirical examination of the relationship between the two. When applied to analyses of the times of material consumption - including the use of energy dependent technologies and the demand for electricity, gas and other fuels - overlooking the material coconstitution of time is an oversight. Developing concepts to understand these specific relationships is my focus here.

The substantive focus on the times of everyday energy consumption is pertinent to current contexts, because the timing of energy demand is an important issue for policy makers and energy providers (Torriti, 2015; Walker, 2014). Until electricity storage becomes a viable option, balancing the production and consumption of electricity remains an environmental and economic challenge. Activating older, carbon intensive power stations in high peak periods is both financially and environmentally costly (Torriti, 2015; Strbac, 2008; Darby and McKenna, 2012). Although renewable generation including solar PV, wind and tidal power - offer a possible means of meeting carbon budgets through altering the electricity supply mix, their temporal patterns (e.g. the diurnal patterns of solar supply) mean that they do not necessarily address challenges of peak demand (Peacock and Owens, 2013). As such, understanding daily, weekly and seasonal patterns of electricity consumption is increasingly on the table (Powells et al 2014; Strengers, 2012; Torriti, 2015; Walker, 2014).

In prominent understandings, peaks are viewed as 'normal', inevitable and unchangeable (Strengers, 2013) and are addressed through energy efficient technologies which meet these demands with the same or less amounts of electricity (Torriti, 2015). Alternatively, peaks are viewed as the cumulative effects of thousands of choices about when to consume, and addressed through pricing tariffs and information which encourage or enable consumers to manage demand and use less energy in peak periods (Strbac, 2008; Darby and McKenna, 2012). More recently, research which draws on time-use data to explore the timing of social practices in relation to peak demand focuses on social and organisational time structures and their effects on temporalities of practice, and ultimately energy consumption (e.g. Anderson, 2016; Torriti, 2017).

Broadly speaking, although I agree with the general direction of travel, these more recent approaches overlook the historical contingency of contemporary temporal structures and patterns of consumption, particularly how materials (e.g. fuel types and technologies) coconstitute such patterns. In this context, this paper argues that an essential starting point for understanding the timing of energy consumption is to understand how materials including fuel type, hot water, warm air, fixtures, fittings and technologies themselves shape, pattern and hold in place temporal characteristics of demand.

This focus has been underscored in recent contributions, which have explored how the coordination of materials has implications for activity sequences of doing laundry (Mylan and Southerton, 2017); and, looked at wood-based heating systems in Finland to demonstrate that technological systems in everyday life have a temporal structuring which is partly ordered by materials (Jalas and Rinkenen, 2016). Dealing with the same conceptual issue, this paper goes a step further than these existing contributions, by 
making materiality the starting point of analysis, and developing a new conceptual vocabulary with which to perceive, analyse and discuss such phenomena.

An in-depth exploratory study of homes and daily lives between 1950 and 2000 designed to focus on materials and time in practice is presented in the paper. In the sections that follow, a description of the research design precedes a fine-grained analysis of the multiple materials woven into accounts of daily routines and specific practices (keeping clean, doing laundry and keeping warm) in different decades. The analysis initially draws on Zerubavel's (1985) four concepts of time, which have been shown by others to be a useful framework for analyzing the temporal characteristics of practices (e.g. Southerton, 2003; Spurling, 2015). These are namely: sequential structures (logically sequenced bundles of tasks), fixed durations (social or institutional expectations about how long a particular event should last), standard temporal locations (when an activity or event happens) and rates of recurrence (how often it happens). Through specific examples that look in detail at how infrastructures, appliances, heat and hot water combine with temporal effects, the Paper identifies some of the ways in which Zerubavel's concepts of time can be deepened through an understanding of the material. The analysis also reveals material temporal effects that this framework cannot explain. In response, I develop an initial conceptual vocabulary that enables these relations to be named, explored and analysed. The relevance of these concepts to contemporary life is discussed.

\section{A Study of Homes and Daily Life between 1950-2000}

To study the relationship of materials and practice temporalities an exploratory retrospective study of houses and daily lives between 1950 and 2000 was undertaken. The study combined archive research of house plans, infrastructures, and household appliances - with retrospective interviews about the daily lives of generations of residents between 1950 and 2000. Retrospective accounts of houses, appliances and daily life from different decades provided examples of multiple materials in practice in days, weeks and seasons. The historical character of these accounts meant they had material features that dramatically contrasted with contemporary circumstances (Southerton, 2009). As such, the turn to history de-familiarised otherwise mundane topics (such as the daily routine and doing laundry) as participants remembered the houses they had lived in, and gave detailed accounts of their daily life whilst living with different fuels and appliances.

The study was conducted in Stevenage, a post-war New Town in South East England built between 1949 and 1970. Its' status as the first post-war new town in the UK is the reason for its rich archive which documents the development of the town and the houses therein. In the context of this paper, Stevenage offered a study site with accurate information about post-war housing, including books of blueprints of all the house types, showing original layout and source of energy, heat and hot water. To study how these houses had been part of daily lives in different decades, fifteen in-depth retrospective interviews were conducted with individuals and couples who had made homes in these houses across the period 1950-2000. The nineteen interviewees were between 35 and 85 years old in 2014, and the interview focussed on their life when they were between the ages of 20 and 35. This resulted in accounts of daily life in different decades, with 
contrasting houses, infrastructure and appliances, but ensured that a similar time of life (moving to a new house and, where applicable, having children) was discussed. This strategy enabled a degree of comparability by focussing on accounts from a similar life course stage, thus foregrounding change in the materiality of daily life, rather than change across the life course ( $\mathrm{nb}$ for a discussion of the latter see Burningham et al, 2014). Participants and the period discussed are outlined in Table 1, some interviewees discussed more than one decade.

\section{Table 1 Overview of the interview participants and decades discussed}

\section{Years discussed in detail}

$1950 \mathrm{~s}$

$1960 \mathrm{~s}$

1970s

1980 s

1990 s

2000s

\section{Interview participants}

Now aged 72

Now aged 80, 76, 75, 72, 66

Now aged 76, 72, 66, 62, 57

Now aged 62, 62, 60, 60, 57

Now aged 60, 44, 39

Now aged 51, 38, 38

A short questionnaire encouraged participants to begin the process of remembering prior to the interview. This was used to collect details of the house that interviewees had lived in when they were 25 years old, with a special focus on household appliances throughout the home, and infrastructures of heat and hot water. To complete the survey participants talked with partners and other family members, looked up dates and addresses and browsed their old photo albums and files.

Building on this foundation, interviews began with the participant giving an overview of their biography including details of houses lived in, who they had lived with, if and when they had children, and if they were involved in paid work (this was drawn as a timeline to refer to in the interview). The house covered in the survey was then positioned on the timeline, explicitly connecting that specific house to the specific time of life. Participants then drew a plan of the house at that time, and they were encouraged to describe its layout, infrastructure (e.g. energy, heat, hot/cold water) and the appliances in each room. These resources, of survey, timeline and house plan, formed the basis of a detailed discussion of the daily life of the interviewee, and other household members, at the time.

Interviewees were prompted to discuss particular themes including daily and weekly routines, who was at home or out at different times of day and why; where they travelled to, for what purpose (e.g. school, work, shopping). Finally, detailed memories about three areas of practice were collected; keeping warm in winter, doing laundry and keeping 
oneself clean. Although the retrospective accounts give something of a generalised view (in real life no two days are quite the same), they also provide fine-grained detail of how infrastructure, house, appliance and practice combined. Memories of past technologies and sources of energy (such as solid fuel fires, immersion heaters, baths, spin driers and twin-tubs) were vivid and enthusiastically discussed by many of the interviewees. As such, despite limitations, the data provides a rich resource with which to analyse some of the ways that materials of daily life co-constitute practice temporalities.

In the analysis that follows, I do not make claims about any particular decade, or social class, nor do I offer insights on general shifts in temporal patterns of social practices across society, the sample size was not large enough for such claims. Instead I talk about how different materials come together in practice, and in doing so shape temporal features of daily life. The insights from the empirical work are presented in two sections. The first takes a specific practice (doing laundry) as the starting point of analysis, and traces the material co-constitution of its sequence, duration, frequency and temporal location, in so doing new concepts of 'pre-practice conversion', 'conversion lag', and 'coordination' are introduced. The second empirical section focusses on a specific room (the bathroom) and traces its temporally fluctuating material qualities, and their implications for the timing of practice. It introduces concepts of 'capacity', 'convergence', 'primary practice temporality' and 'secondary temporal effects'.

\section{How materials co-constitute times of doing laundry and keeping}

\section{warm}

The interviews explored how practices of doing laundry and keeping warm in winter at home were accomplished with different infrastructures and appliances. The paragraphs below discuss two examples in detail, the first focuses on doing laundry with a twin-tub. The second contrasts keeping warm in winter with a solid fuel fire and gas central heating. The analysis reveals that the temporal location of social practices is partly an outcome of their sequence and duration. To understand the material constitution of these temporal structures requires new concepts of pre-practice conversion, conversion lag and coordination.

The twin-tub washing machine was a common domestic technology in the 1950s and 1960s, discussed by eight of the interviewees. It was gradually replaced by the automatic washing machine in the 1970s and 1980s. The practice of doing laundry with a twin tub had a particular set of tasks of fixed sequence and duration associated with it. Twin tubs were free-standing appliances which interviewees stored in the corner of a kitchen or store room and 'wheeled-out' into the kitchen for use. They had hose pipes which attached to taps and fed waste water into buckets. To use the appliance the left hand drum was filled with soap suds and hot water. In most cases the water was heated with an electric immersion heater in a tank in the airing cupboard, which was switched on an hour before needed.

Starting with the least dirty load, the clothes were mechanically washed. The same hot water was used to do all the loads, because of the cost of heating water and the small size of the water tank. Combined with the effort of setting up the machine in the first place, 
which was not a task that the interviewees wanted to repeat more than once a week, it made sense to do all the washing in one go and to re-use hot water for this purpose. 'Giant wooden tweezers' were used to unload the clothes (because the water was hot). After everything had been washed, the water was drained into a bucket. The tub would then be refilled with hot water for a first rinse (of multiple loads) then cooler water for a second rinse. Clothes were transferred to the right side of the machine for spinning. Finally the laundry would be hung out in the garden or around the house for drying. Interviewees spoke of the laundry being a long job which took all day. Where a household member (generally female) was at home in the week this would be done on a weekday, once women's work became common place the only time the washing could be done was at the weekend.

The process of doing laundry with a twin tub highlights several ways that materiality coconstitutes the timing of laundry practice. First of all, laundry required pre-practice conversion of spaces, technologies and water. Pre-practice conversion is a concept I propose to refer to the reconfiguration of materials to organise them into the arrangement required for a practice. It requires practical effort from the practitioner. Rather than the permanent location of the contemporary 'plumbed-in' automatic washing machine, the twin tub was stored, and brought into the kitchen for use. The machine was placed in the centre of the kitchen and attached to water taps with a waste pipe in a bucket or sink. This temporarily transformed the kitchen which meant that many other kitchen practices were no longer possible. In similar vein, four of the interviewees spoke of making a drying room of the living room at night time in the winter:

"... in the winter months I had a solid fuel stove and a big airer that opened up like a butterfly... we used to add some fuel to the fire and put it up before we went to bed." (Grace, discussing the early 1970s)

It is partly because of the effort involved in setting up these laundry and drying spaces, and the inconvenience caused by such 'set-ups' that it made sense to do all of the washing in one go, thus giving laundry a long duration. This had implications for how the kitchen and other (e.g. drying) space could be used for other activities in daily and weekly schedules.

The requirement to convert some forms of materiality (e.g. cold water into hot water) before the material (water) was ready to be consumed also added to the duration of doing laundry. I refer to this as conversion lag to note the time lag between human intervention (switching on the immersion heater) and effect (hot water). In this example, the immersion heater had to be switched on an hour before the hot water was needed. Conversion lags add to the duration of a practice performance, in this instance further emphasising the fact that laundry was a task which needed planning into weekly schedules.

Coordination of materials and people in practice is important for the temporal location and rate of recurrence of the practice too, a point that has been noted in recent studies of contemporary laundry practices (Mylan and Southerton, 2017). As noted, the pre-practice conversion required of the kitchen, and the conversion lag associated with making hot 
water resulted in performances of laundry practice with long durations, as a result laundry was coordinated into one day of the week. Before the automatic washing machine, doing laundry required frequent human intervention, meaning that a practitioner had to be present for a whole day. This human presence meant laundry had to be coordinated with work practices, as well as accumulations of dirty laundry and other household practices (so that the kitchen could be used for the whole day).

Another reason for such coordination was to do with economies of scale and the cost of heating a tank of water. Laundry was accumulated and the same water re-used for multiple loads to save costs. In this instance the material (hot water) and its associated cost structured how laundry was organised, with implications for its temporal features (specifically its long duration, and coordination around one tank of hot water).

Keeping warm in winter likewise revealed how temporalities of a practice are shaped by the material world. The time of life which the interviewees discussed coincided with a range of home heating technologies. Seven of the interviewees had lived with a solid fuel fire which had provided single-room heat to the living room. Keeping warm with a solid fuel fire was a process which involved work and time. Pre-practice conversion of the fireplace into a prepped fire involved bringing in kindling and coal (or other solid fuel), rolling newspaper, laying the fire and lighting it. Subsequent work involved 'getting it going' and then 'tending'. As with the immersion heater and hot water, there was a conversion lag between getting the fire going and the room feeling warm, as one interviewee recalls:

"I remember we got home one night, it was absolutely freezing, so we lit the fire, but it didn't get warm until we went to bed" (Kenneth, discussing the early 1960s)

This time and effort, combined with the cost of solid fuel, created particular routines of heating the home focussed on the coordination of heat and people. Interviewees spoke of putting up with the cold at certain times of day (in the morning, throughout the daytime), in certain situations (if they were the only member of the household at home), and in certain spaces of the house (in the kitchen and upstairs). They spoke of only lighting the fire when they returned home for the evening, if the return of other household members was anticipated, or if they were staying home with children. Interviewees also discussed how the fire coordinated the household too. In particular, it was common to heat just one room of the home, managing the heat using doors and various kinds of draught excluder, with all the household members using the heated room (Kuijer and Watson, 2017).

In these examples materials of doing laundry and keeping warm have implications for sequences, durations, frequencies and temporal locations of practice which can be explained by concepts of pre-practice conversion, conversion lags and coordination. In the next section I turn attention away from specific practices to a specific room of the house; the bathroom. As such, the material qualities of space are brought into the analysis of practice timings. 


\section{The material qualities of the bathroom and times of practice}

The houses of the new town which formed part of this study were designed in the late 1940s and built between 1950 and 1970. The provision of on-demand electric light was therefore standard. Such illumination meant that many practices had already spread out from hours of daylight into darkness, creating new daily and seasonal timings of practice. This section of the paper explores parallel changes in home heating and hot water which occurred across the period of this study. Focussing on the bathroom, this section finds that different combinations of fuel types and technologies endowed the bathroom with temporally fluctuating qualities of heat and hot water, with implications for the timing of social practices of keeping oneself clean.

Built from the 1950s onwards, all of the houses in Stevenage had an indoor toilet and an indoor upstairs bathroom containing a bath and sink. In accounts from the 1950s and 1960s, hot water was made in a back boiler above a solid fuel open fire or stove, which fed an insulated water tank in an upstairs airing cupboard. The production of hot water and home heat were closely coupled. Hot water was available when the fire was lit, and for a short time afterwards. From the early 1960s immersion heaters were fitted in water tanks. In this arrangement, hot water and home heat were decoupled by design, however, such hot water heaters were expensive to use, and usage involved the conversion lags described above.

Gas central heating was subsequently introduced, taking a variety of forms. When introduced with an insulated hot water tank, water was heated whilst the gas central heating system was on, and stored in the tank, being topped up by an immersion heater at other times. In other systems, the production of heat and water could either be coupled or uncoupled, so hot water was always made by the gas boiler, but sometimes whilst the heat was on (e.g. in the winter), and sometimes with the heating turned off (in the summer). Finally, in the 2000s combi boilers began to replace the boiler-water tank arrangement. They provide 'on-demand' hot water which is instantly heated at moment of use. The central heating is also 'on-demand' though often controlled using a timer switch. In addition to these systems, electric showers became available from the 1980s, and were discussed alongside a variety of other hot water technologies by interviewees. Table 2 summarises the bathroom practices discussed by the interviewees and the combinations of infrastructures and technologies involved. 
Table 2: Bathroom Practices, Infrastructures and Technologies

\begin{tabular}{|c|c|c|c|c|}
\hline Bathroom practices & $\begin{array}{l}\text { Form of } \\
\text { space } \\
\text { heating }\end{array}$ & $\begin{array}{l}\text { Heated } \\
\text { bathroom } \\
\text { space? }\end{array}$ & $\begin{array}{l}\text { Form of hot } \\
\text { water }\end{array}$ & Appliance \\
\hline $\begin{array}{l}\text { Morning 'camper's } \\
\text { wash' } \\
\text { Weekday evening bath } \\
\text { Sunday bath } \\
\text { Re-use of bath water }\end{array}$ & $\begin{array}{l}\text { Solid fuel fire } \\
\text { (living room) }\end{array}$ & $\mathrm{N}$ & $\begin{array}{l}\text { Back boiler } \& \\
\text { water tank }\end{array}$ & $\begin{array}{l}\text { Sink } \\
\text { Bath }\end{array}$ \\
\hline $\begin{array}{l}\text { Morning 'camper's } \\
\text { wash' } \\
\text { Weekday evening bath } \\
\text { Sunday bath } \\
\text { Re-use of bath water }\end{array}$ & $\begin{array}{l}\text { Solid fuel fire } \\
\text { plus back } \\
\text { boiler \& } \\
\text { radiator }\end{array}$ & $\mathrm{N}$ & $\begin{array}{l}\text { Back boiler } \\
\text { Water tank } \\
\text { Immersion } \\
\text { heater }\end{array}$ & $\begin{array}{l}\text { Sink } \\
\text { Bath }\end{array}$ \\
\hline $\begin{array}{l}\text { Morning 'camper's } \\
\text { wash' } \\
\text { Bath or shower in } \\
\text { evening }\end{array}$ & $\begin{array}{l}\text { Electric } \\
\text { Storage } \\
\text { Heaters }\end{array}$ & $\mathrm{N}$ & $\begin{array}{l}\text { Water tank } \\
\text { Immersion } \\
\text { heater }\end{array}$ & $\begin{array}{l}\text { Sink } \\
\text { Bath } \\
\text { Shower } \\
\text { (from water } \\
\text { tank) } \\
\end{array}$ \\
\hline $\begin{array}{l}\text { Morning and evening } \\
\text { showers (coordinated } \\
\text { around limited hot } \\
\text { water) } \\
\text { Less regular bathing }\end{array}$ & $\begin{array}{l}\text { Gas central } \\
\text { heating }\end{array}$ & $Y$ & $\begin{array}{l}\text { Gas central } \\
\text { heating fills } \\
\text { water tank }\end{array}$ & $\begin{array}{l}\text { Sink } \\
\text { Bath } \\
\text { Shower } \\
\text { (from water } \\
\text { tank) }\end{array}$ \\
\hline $\begin{array}{l}\text { Morning showers } \\
\text { (showers short as water } \\
\text { can run out) } \\
\text { Less regular bathing }\end{array}$ & $\begin{array}{l}\text { Gas central } \\
\text { heating }\end{array}$ & $Y$ & $\begin{array}{l}\text { Water tank } \\
\text { Immersion } \\
\text { heater }\end{array}$ & $\begin{array}{l}\text { Sink } \\
\text { Bath } \\
\text { Shower } \\
\text { (from water } \\
\text { tank) } \\
\end{array}$ \\
\hline $\begin{array}{l}\text { Morning showers } \\
\text { Evening baths for } \\
\text { children }\end{array}$ & $\begin{array}{l}\text { Gas central } \\
\text { heating } \\
\text { (combi) }\end{array}$ & $Y$ & $\begin{array}{l}\text { Gas central } \\
\text { heating } \\
\text { (combi) \& } \\
\text { electric } \\
\text { shower }\end{array}$ & $\begin{array}{l}\text { Sink } \\
\text { Bath } \\
\text { Shower }\end{array}$ \\
\hline
\end{tabular}

With a solid fuel fire and back boiler, home heating and hot water were temporally synchronised. As previously explained, there was little point lighting the fire in the morning when the household was out for the day. Therefore, with this combination of infrastructure and technology, interviewees reported morning routines involving a 'campers-style', or 'top and tail' wash (meaning the use of cold water and a flannel to wash the face, neck and body), with baths being taken in the evening or at the weekend. The quote below illustrates the use of bathrooms discussed by seven interviewees: 
"I must admit we didn't wash as much then, we did wash but it was more of an all over wash with a flannel. You didn't bath or shower everyday. I remember bathing 2 or 3 times a week, and I remember only washing my hair once a week". (Joan, discussing the 1970s)

Obviously a lack of hot water in the morning was a key reason for this, which was an outcome of the open fire being organized around the practice of keeping warm. I refer to this as the primary practice temporality, to highlight the primary practical purpose around which the timings of a technology's use are organised (nb. the primary practice can only be identified through empirical study and is not pre-determined by the technology itself). The temporalities of keeping warm with a solid fuel fire are outlined in the previous section. As noted, primary practice temporalities have secondary temporal effects, in which the temporal structures of the primary practice are mirrored in other practices reliant on the same technology. In this case the timing of hot water, which is in synchrony with lighting the fire, impacts the forms and temporality of washing practices across the day and week.

Such secondary effects provide an explanation of baths being coordinated with the lighting of the fire. However, the study found that these routines initially continued even once hot water was decoupled from the fire by immersion heaters. This was for several reasons. First of all, the conversion lag created by the immersion heater initially held patterns of morning wash and evening or weekend baths in place.

"The immersion would be to heat the water, they weren't on timers... you just plugged it in" (Grace, discussing the 1970s).

This conversion lag, combined with the time it took to run and have a bath, meant that the duration of bathing was inconvenient in the morning. Furthermore, infrastructure had a different capacity then. In this paper I use capacity to refer to the amount that an infrastructure can provide or contain. The water tanks of the homes in the 1960s and 1970s discussed in this paper contained enough hot water to fill a single bath. Similar to doing laundry, the cost of hot water meant that re-use of the water for multiple people was normal. Thus bathing a household meant the coordination of bath, hot water and household members so that multiple household members could bathe one after another using the same water. This further added to the duration of bathing which retained its evening slot even when it was released from the primary practice temporality of keeping warm.

Even so, this pattern of evening all-over washing persisted when showers were introduced too. Concepts of conversion lags, capacity and coordination do not apply here, but the idea of convergence helps to explain this persistence. Convergence refers to combinations of material that specific practices are deemed to require. The accounts offered in this study suggested that all-over washing requires a convergence of both hot water and heat. It is only once bathrooms were heated, and hot water was available in the morning (either from a timed immersion heater or timed gas central heating) that morning 
showers were discussed as a regular occurrence. For example, an interviewee who described living with a combi boiler, electric shower and gas central heating in the 2000s explained how the bathroom was heated before the family rose, with hot water in limitless quantities available on-demand:

"...the heating is on a timer so the heating will have come on at about a quarter to seven. So the house will have been warming up... we use a combination boiler so we don't have to worry about hot water... you get it on demand which is great actually" (David, discussing the 2000s)

The case of changing bathroom practices demonstrates that home heating and hot water endow rooms with temporally fluctuating material qualities. Such temporalities need to be understood in terms of the primary practice for which a technology is used (in this case, fires for heat). However, as shown in the example, the secondary effects of primary practice temporalities can sometimes conceal forms of convergent materiality that are viewed as essential for practice. In the example heated space and hot water are important for showering, especially in the winter, and so the technical decoupling of heat and hot water did not initially result in changed patterns of practice. However, eventually as heat and hot water became available on demand bathrooms changed from mainly being used in the evenings and on Sundays, to being in regular use each morning. Such shifts have already been noted by others (e.g. Shove, 2003; Hand and Shove, 2007). The current analysis extends these accounts by demonstrating that multiple materials of gas, electric, heat, hot water, showers, sinks and baths, combine to create a temporally fluctuating material environment, made up of pre-practice conversions, conversion lags, capacities, convergences, primary practice temporalities and their secondary temporal effects.

\section{Conclusion}

The paper seeks to reverse an emphasis in recent discussions of peak demand, renewable supply and the times of everyday energy consumption, which suggest that the use of technologies, infrastructure and energy, is patterned by the temporal features of practice as against these materials being integral to such practice temporalities. Through an exploratory retrospective study of houses and daily lives between 1950 and 2000 the paper reveals some of the ways in which multiple forms of materiality (including electricity, solid fuel, hot water and heat, as well as technologies and objects) are used and consumed in practice. The paper specifically focusses on the temporal characteristics of material consumption, and the mutual shaping of temporality and materiality in practice. These mundane details of daily life are made visible by exploring a historical period when the materiality of the home, including types of fuel, domestic infrastructures, fixtures, fittings and domestic technologies were remarkably different to today.

The paper extends recent advancements in practice theory (Hui et al, 2017) by drawing temporality and materiality of practice into the same frame. The paper explicitly analyses the varieties of material that form part of specific practices (including doing laundry and keeping warm in winter) and how forms of materiality combine (specifically in the bathroom) with temporal effects. In contrast to the sociological concepts of time in Zerubavel's work (1985) the paper demonstrates that temporal locations, durations, 
sequences and rates of recurrence are inherently material. It is through understanding the dynamic material shaping of these temporal features of everyday life, that the role of 'matter' in the timing of consumption can be understood. Moreover, in contention with the static temporal structures depicted by Zerubavel $(1979 ; 1985)$, the study suggests that temporal structures are historically contingent, and that the changing materiality of practices is central to dynamics of changing temporalities.

The focus on materiality and time offers a powerful counterpoint to the extant literature on peak demand. Here, attention has been on the recurring temporal locations of electricity consumption, and on the behaviours that might be changed or shifted from peak periods. This paper reveals a more specific and nuanced account. Rather than conceptualising temporal patterns as constituted from choices and behaviours about when to do things, and rather than seeing temporal patterns of practice as overlaying and consuming the material world in synchrony with their own rhythms, the paper demonstrates that, in practice, materiality and temporality are intimately connected and mutually shaping. To put it another way, when we start with materiality - fuel, houses, fixtures, fittings, technologies - the material relations which shape the temporal features of everyday practice are revealed; so too is the two-way relationship between everyday practice and material consumption. Practices, whose timings are shaped by materiality, are adjusted and structured to influence when and how materials are brought into use, and ultimately when energy is consumed.

The paper argues that nuanced understanding of the material-temporal relationship requires more than a materialised explanation of existing temporal concepts. As such, a modest new conceptual vocabulary is proposed as follows:

Pre-practice conversion refers to the conversion of materiality which requires practical effort from the practitioner. An example in this study was the rearrangement of the kitchen to create a laundry room before 'doing laundry' could begin. In this study, the inconvenience of pre-practice conversion had implications for the organisation of practices, especially their duration and rate of recurrence, as tasks were accumulated and then done in one go.

Conversion lag refers to conversions of materiality, which though initiated by the practitioner involve a time lag before the converted material can be consumed in practice. For example, when electricity is converted to hot water via a switch on an immersion heater, and when solid fuel is converted into warm air through the making of a fire, the moment of action and effect are temporally separated. In this study, conversion lags had implications for the overall duration of practice performance, the co-ordination of people and materials in practice and thus for the temporal location of practices in the day and week.

Primary practice temporality refers to the primary practical purpose of a technology around which the timing of the technology's use is organised. For example, the primary practice temporality of the solid fuel fire was organised around keeping warm, even though the fire was also essential for making hot water. 
Secondary temporal effects are related to primary practice temporalities. The term refers to the mirroring of such primary temporal structures in other practices that are reliant on the same technology. As such the temporal features of the secondary practice are organised by the primary practice. In this study this had implications for the temporal location of bathing, and subsequently showering, in the evening in winter, and for the practice of 'top $\mathrm{n}$ tailing' that could be performed each morning in the cold.

Convergence refers to the combinations of material that specific practices have come to 'require' for their performance. For example, in this study heated space and hot water appear to be convergent materials of showering ( $\mathrm{nb}$. this was not the case for top $\mathrm{n}$ tailing above). In this case the initial temporal location of showering in the evening might have been assumed to be a secondary temporal effect, until the technical (and thus temporal) separation of heat and hot water revealed a convergent relation between the two.

Capacity refers to the limits of the infrastructure; the amount the infrastructure can contain or produce. For example, the amount of water that a water tank can hold, and thus the amount of hot water available in one go.

Co-ordination refers to the intentional organisation of materials and people in practice. Such coordination was found in relation to capacity (as a way to organise practices around limited materials), but equally coordination was drawn on to ensure prudence in material consumption - accumulating tasks to create an economy of scale. In this study this had implications for the temporal location of bathing in the week, which with a small water tank, was done when all family members were available to bathe one after another.

Although this small scale exploratory study has enabled the development of these concepts, there are still some important issues that it is not possible to address within the confines of this article. I do not present a set of procedural rules for determining what counts as 'materiality' within practices and what does not, though I do include different types of fuel, hot water, warm air, fixtures, fittings, technologies and objects within my account. The purpose of this article has not been to advance a developed theory of materiality in practices but rather to anticipate how we might analyse the temporalities of practice, consumption - and specifically energy consumption - differently if we take materiality as our starting point.

Likewise, the article does not set out the broad spectrum of influences which have implications for the temporal organisation of daily life, which might include the timetables of schools and workplaces, time-related policies and the life-course of family members. Of course such temporal structures (which are also dynamic) have important implications for the timing of social practices in the home too. These topics have been covered elsewhere (e.g. Breedveld, 1998; Burningham et al, 2014; Mylan and Southerton, 2017; Nicholls and Strengers, 2015; Torriti, 2015;), the focus of this paper is to specifically reveal some of the ways in which temporality is material. The article demonstrates that materiality has a distinctive role in the temporal stitching of social 
practices, and that social practices influence the timing of material consumption and usage.

In drawing on examples of the past, a final point of reflection is whether the material relations and conceptual vocabulary developed in the paper are relevant today. With the development, initially of timer switches for home heating, hot water and other devices, and more recently of the smart grid, it could be argued that the implications of 'the material' for temporalities of practice and consumption are much less significant in contemporary homes and daily lives than those discussed in this study. However, this is not the conclusion to be drawn from the preceding analysis.

Rather, the point to take away is that the relation of materiality and temporality always exists in practice, although the precise instantiation of such dynamics remains a topic for empirical research. It is certainly the case that contemporary lives are different to those depicted in this paper. However, there is no such thing as 'the contemporary home'. Rather, as was the case for the homes in this study, layers of materiality exist which develop and change across time. Different generations modify, adapt, extend, renovate and purchase/use new technologies and objects (Hand et al, 2007; Nansen et al, 2011) so that at any moment, a broad variety of 'homes' exists. Such variety will continue in the future as new technical developments are woven into everyday life in different and uneven ways. Such materials in practice always imply temporal features, and have implications for the timing of material consumption and use. It is therefore inescapable that such dynamics continue to shape the contemporary world. As such, this article offers a conceptual orientation and initial vocabulary with which to explore such matters of time, and their implications for the temporal organisation of energy consumption, both now and in changed material and practice contexts in the years to come.

\section{Acknowledgements}

I am especially grateful to Anna Carlsson Hyslop for the archive research that provided background to this paper, for discussions with Lenneke Kuijer, Elizabeth Shove, Frank Trentmann and Matt Watson, and for comments from Stanley Blue, Allison Hui, Janine Morley, the DEMAND Research Centre reading group (www.demand.ac.uk) and the reviewers. The interview materials relating to this Paper are available on the UK Data Service http://reshare.ukdataservice.ac.uk/852575/

\section{Funding Acknowledgements}

This work was supported by the Engineering and Physical Sciences Research Council [grant number EP/K011723/1] as part of the RCUK Energy Programme and by EDF as part of the R\&D ECLEER Programme.

\section{References}

Anderson, B. (2016) Laundry, energy and time: Insights from 20 years of time-use diary data in the United Kingdom, Energy Research and Social Science, 22:125-136. 
Breedveld, K. (1998) The Double Myth of Flexibilization: trends in scattered work hours and differences in time sovereignty, Time and Society, 7(1): 129-143.

Burningham, K., Venn, S., Christie, I., Jackson, T., Gatersleben, B. (2014) New motherhood: A moment of change in everyday shopping practices?, Young Consumers, 15(3): 227-238.

Darby, S.J. and McKenna, E. (2012) Social implications of residential demand response in cool temperate climates, Energy Policy, 49:759-769.

Fine, G. (1990) Organizational time: Temporal demand and the experience of work in restaurant kitchens, Social Forces, 69(1): 95-114.

Hand, M., Shove, E. and Southerton, D. (2005) Explaining showering: a discussion of the material, conventional and temporal dimensions of practice, Sociological Research Online, 10(2).

Hand, M., Shove, E. and Southerton, D. (2007) Home Extensions in the United Kingdom: Space, time and practice, Environment and Planning D, 25:668-681.

Hui, A., Schatzki, T. and Shove, E. (2017) Introduction in Hui, A., Schatzki, T. and Shove, E. (Eds) The Nexus of Practice: Connections, constellations, practitioners, Routledge: London.

Jalas, M. (2006) The art of loving wooden boats, Time and Society, 15(2-3): 343-363.

Jalas, M. and Rinkenen, J. (2016) Stacking wood and staying warm: Time, temporality and housework around domestic heating systems, Journal of Consumer Culture, 16(1): 43-60.

Kuijer, L. and Watson, M. (2017) 'That's when we started to use the living room: Lessons from a local history of domestic heating in the United Kingdom', Energy Research and Social Science, 28:77-85.

Maller, C., Nicholls, L. and Strengers, Y. (2016) Understanding the Materiality of Neighbourhoods in 'Healthy Practices': Outdoor Exercise Practices in a New Masterplanned Estate, Urban Policy and Research, 34(1):55-72.

Mylan, J. and Southerton, D. (2017) The Social Ordering of an Everyday Practice: The case of laundry, Sociology, 1-18.

Nansen B, Arnold M, Gibbs M, et al. (2011) Dwelling with media stuff: latencies and logics of materiality in four Australian homes. Environment and Planning D: Society and Space 29: 693-715. 
Nicholls, L. and Strengers, Y. (2015) Peak demand and the family peak period in Australia: understanding practice (in) flexibility in households with children, Energy Research and Social Science, 9:116-124.

Peacock, A.D. and Owens, E.H. (2013) Assessing the potential of residential demand response systems to assist in the integration of local renewable energy generation, Energy Efficiency, 7:547-558.

Powells, G., Bulkeley, H., Bell, S. and Judson, E. (2014) Peak electricity demand and the flexibility of everyday life, Geoforum, 55:43-52.

Reckwitz, A. (2002) Toward a theory of social practices: a development in cultural theorizing, European Journal of Social Theory, 5(2): 243-263.

Schatzki, T. (1996) Social practices: a Wittgensteinian approach to human activity and the social, New York: Cambridge University Press.

Schatzki, T. (2010) Materiality and Social Life, Nature and Culture, 5(2):123-149.

Shove, E. (2003) Comfort, Cleanliness and Convenience: The social organization of normality, Berg: Oxford, New York.

Shove, E., Pantzar, M. and Watson, M. (2012) The Dynamics of Social Practice: Everyday life and how it changes, Sage: London.

Shove, E. and Spurling, N. (2013) Sustainable Practices: Social theory and climate change, London:Routledge.

Shove, E., Trentmann, F. and Wilk, R. (2009) Time, Consumption and Everyday Life: Practice, materiality and culture, Oxford: Berg.

Shove, E. and Walker, G. (2014) What is Energy For? Social practice and energy demand, Theory, Culture and Society, 31(5):41-58.

Southerton, D. (2003) Squeezing Time: Allocating Practices, Coordinating Networks and Scheduling Society. Time \& Society 12: 5-25.

Southerton, D. (2009) Re-ordering Temporal Rhythms: Coordinating daily practices in the UK in 1937 and 2000, In E. Shove, Trentmann, F. and Wilk, R. Time, Consumption and Everyday Life: Practice, materiality and culture. Berg: Oxford \& New York.

Spurling, N. (2015) Differential Experiences of Time in Academic Work: How qualities of time are made in practice, Time and Society, 24(3):367-389. 
Strbac, G. (2008) Demand side management: benefits and challenges, Energy Policy, 36:4419-4426.

Strengers, Y. (2011) Negotiating everyday life: The role of energy and water consumption feedback, Journal of Consumer Culture, 11(3):319-338.

Strengers, Y. (2012) Peak electricity demand and social practice theories: reframing the role of change agents in the energy sector, Energy Policy, 44:226-234.

Strengers, Y. (2013) Smart Energy Technologies in Everyday Life: Smart Utopia?, Palgrave MacMillan: London.

Strengers, Y., Nicholls, L. and Maller, C. (2014) Curious energy consumers: Humans and nonhumans in assemblages of household practices, Journal of Consumer Culture, 16(3):761-780.

Torriti, J. (2015) Peak Energy Demand and Demand Side Response, Routledge, London.

Torriti, J (2017) Understanding the timing of energy demand through time use data: Time of the day dependence of social practices Energy Research \& Social Science, 25:37-47.

Walker, G. (2014) The dynamics of energy demand: change, rhythm and synchronicity, Energy Research and Social Science, 1:49-55.

Warde, A. (2005) Consumption and theories of practice, Journal of Consumer Culture, 5(2): 131-153.

Zerubavel E. (1979) Patterns of Time in Hospital Life, Chicago \& London: The University of Chicago Press.

Zerubavel E. (1985) Hidden Rhythms: Schedules and Calendars in Social Life, London: University of Calinfornia Press Ltd. 